\title{
Iron absorption from maize (Zea mays) and sorghum (Sorghum vulgare) beer
}

\author{
BY D. P. DERMAN, T. H. BOTHWELL, J. D. TORRANCE, \\ W. R. BEZWODA, A. P. MACPHAIL, M. C. KEW, M. H. SAYERS, \\ P. B. DISLER AND R. W. CHARLTON \\ South African MRC Iron and Red Cell Metabolism Unit, Department of \\ Medicine and Pharmacology, University of the Witwatersrand, Johannesburg, \\ South Africa
}

\section{(Received Io May 1979-Accepted 3 November 1979)}

I. Iron absorption from maize (Zea mays) and sorghum (Sorghum vulgare) beer was more than twelvefold greater than from a gruel made from the constituents used to prepare the beer.

2. The effect of changes occurring during brewing were investigated. These changes include a decrease in the solid content, and the formation of $30 \mathrm{ml}$ ethanol $/ 1$ and $5 \mathrm{ml} \mathrm{lactic} \mathrm{acid/l.}$

3. The presence of solid material was found to inhibit Fe absorption markedly, especially when the solid content was $100 \mathrm{~g} / \mathrm{l}$ or more.

4. The presence of ethanol potentiated Fe absorption but the effect was only modest in gruels with a high solid content.

5. Fe absorption from a $2 \mathrm{ml}$ lactic acid/l solution was four-fold greater than from a hydrochloric acid solution of the same $\mathrm{pH}$. When lactic acid was added to a gruel containing $200 \mathrm{~g}$ solids/ 1 the mean absorbtion rose from 0.4 to $1 \cdot 2 \%$

6. In a direct comparison, $\mathrm{Fe}$ absorption from beer was significantly better than from a gruel of similar pH containing lactic acid.

7. The results suggest that at least three factors are responsible for the enhanced Fe absorption from maize and sorghum beer. These include the removal of solids during fermentation and the presence of ethanol and of lactic acid in the final brew.

8. In order to reproduce the way in which beer is brewed domestically in Fe containers, a study was done in which beer was prepared in the presence of $\mathrm{Fe}$ wire. Under such circumstances Fe was rapidly dissolved and the final Fe concentration of the brew was $89 \mathrm{mg} / \mathrm{l}$. However, the nature of the Fe-containing compound or compounds was not elucidated.

The black population of Southern Africa provides a notable exception to the rule that iron deficiency is prevalent in populations subsisting on cereal-based diets (Walker \& Arvidsson, I953; Bothwell \& Isaacson, 1962; Buchanan, 1969). Although the staple food of this population is maize, Fe overload is common and this had been ascribed to an excessive dietary intake of Fe. The Fe has been shown to be derived from the utensils used for the preparation of food and traditional alcoholic beverages (Walker \& Arvidsson, 1953; Bothwell et al. 1964). Beer made from maize (Zea mays) and sorghum (Sorghum vulgare) which contains an average of $40 \mathrm{mg} \mathrm{Fe} / \mathrm{l}$, seems to be the major source, since there is a correlation between the extent of the Fe overload and the quantities consumed. Furthermore, a decline in the consumption of this beer over the last 17 years and its replacement by Western-type liquors has been associated with a decrease in both the prevalence and severity of Fe overload (MacPhail et al. 1979).

The results of several other studies have shown that the Fe in cereals such as maize is poorly absorbed, even by Fe-deficient subjects (Layrisse et al. 1969; Layrisse et al. 1973; Sayers et al. 1973), and any fortification-Fe that is added to cereals is equally poorly absorbed (Layrisse et al. I973). On this basis, it is surprising that Fe overload is so common in the black populations of Southern Africa, since maize is the staple foodstuff, being consumed as porridge and together with sorghum in the indigenous beer. In the previous study it was 
shown that very little of the Fe present in porridge is absorbed (Sayers et al. 1973). The purpose of the present study was to find out the bioavailability of the $\mathrm{Fe}$ in the traditional beer.

\section{EXPERIMENTA L}

\section{Preparation of beers and gruels}

The traditional beer consumed by the black population of Southern Africa, which is currently maize and sorghum beer, differs from the beers of Europe or America. It is brewed from a mixture of maize and sorghum in proportions which vary according to local custom; usually there are I-2 parts maize:I part sorghum. Part or all of the sorghum is malted, and this results in an increase in the enzyme content which accelerates the conversion of the starch to sugars. There are two sequential fermentations. The first is a lactic acid fermentation mediated by a Lactobacillus in the grain. The fermentation is initiated by making a mixture of the maize and sorghum in hot water and allowing it to stand for $1-2 \mathrm{~d}$ in a warm place. (The optimal temperature for this reaction is close to $50^{\circ}$ ). During this period the mixture turns sour as a result of the formation of lactic acid and the $\mathrm{pH}$ falls from near neutral to approximately 3.5 . This soured gruel is then boiled for $2 \mathrm{~h}$, which gelatinizes the starch and sterilizes the brew. After cooling, the malted sorghum is added and this converts gelatinized starch to sugar. The malted sorghum also inoculates the brew with yeast, and the alcoholic fermentation commences. After I-2 d in a cool place (approximately $20^{\circ}$ ) the beer is filtered through a woven-grass filter, and is then ready for consumption.

In urban areas the beer is brewed commercially on a large scale. To obtain a uniform product and to optimize production, pure-cultured Lactobacillus delbruckii is added to initiate the first fermentation, and brewer's yeast is used to start the second fermentation. Much of the insoluble material is removed on centrifugal filters, but the yellow-pink final product is opaque and still contains approximately $50 \mathrm{~g}$ suspended solids/l.

In the present investigation the effect of the changes during the brewing of beer on the bioavailability of added radio $\mathrm{Fe}\left(3 \mathrm{mg} \mathrm{Fe}\right.$ as $\mathrm{FeCl}_{3} .6 \mathrm{H}_{2} \mathrm{O}$ labelled with $2.5 \mu \mathrm{Ci}{ }^{59} \mathrm{FeCl}_{3}$ or with $2.5 \mu \mathrm{Ci}^{55} \mathrm{FeCl}_{3}$ per subject) (Radiochemical Centre, Amersham, Bucks) was studied. The radio-isotopes were added to the maize and sorghum gruel or to one of its fermentation products, the proportions of cereals and the method of preparation being varied from experiment to experiment. Details of the preparation of these various products are as follows.

Gruels. In different experiments gruels with differing proportions of solids were used. The thickest one ( $162.5 \mathrm{~g}$ solids/1) was similar to that used in the preparation of commercial beer, and was prepared by boiling $40 \mathrm{~g}$ maize meal and $25 \mathrm{~g}$ sorghum in water for $25 \mathrm{~min}$ to give a final volume of $400 \mathrm{ml} / \mathrm{subject}$. The Fe was added before cooking.

The second gruel ( $100 \mathrm{~g}$ solids/l) was prepared from $20 \mathrm{~g}$ maize meal, $10 \mathrm{~g}$ malted sorghum, $0.1 \mathrm{~g}$ brewer's yeast and $50 \mathrm{ml}$ Lactobacillus delbruckii culture. The maize meal was allowed to soak for $10 \mathrm{~min}$ in water to which the ${ }^{59} \mathrm{FeCl}_{3}$ had been added, boiled for $2 \mathrm{~h}$ and then cooled. The yeast and Lactobacillus culture, both of which had been boiled to destroy enzyme activity, were added together with ro g sorghum and the volume was adjusted to $300 \mathrm{ml}$ immediately before ingestion.

Soured gruel (100 $\mathrm{g}$ solids/l) was prepared as follows: $20 \mathrm{~g}$ maize meal was soaked for Io min in water to which the ${ }^{59} \mathrm{FeCl}_{3}$ had been added, boiled for $2 \mathrm{~h}$ and then cooled to $50^{\circ}$. The Lactobacillus culture was then added together with $5 \mathrm{~g}$ malted sorghum, and the temperature was maintained at $50^{\circ}$ for $24 \mathrm{~h}$. It was then cooled to room temperature and boiled yeast together with a further $5 \mathrm{~g}$ malted sorghum were added shortly before administration.

The thinnest gruel ( $33 \mathrm{~g}$ solids/l) was prepared by boiling $10 \mathrm{~g}$ each of maize meal and 
sorghum in $200 \mathrm{ml}$ water for $25 \mathrm{~min}$. It was then made up to $600 \mathrm{ml}$ with either water or commercially prepared beer containing labelled $\mathrm{FeCl}_{3}$. A small amount of sodium chloride and three saccharine tablets were added to make the mixture more palatable.

Beers. Two forms of beer were used. Commercial beer was obtained from the brewery (West Rand Administration Board, Langlaagte Brewery) immediately after filtration at the start of the alcoholic fermentation. The Fe was added and fermentation was allowed to continue for 24-32 $\mathrm{h}$ before administration.

The beer that was prepared in the laboratory was made from the soured gruel described previously. After the $24 \mathrm{~h}$ Lactobacillus fermentation, the gruel was boiled for $2 \mathrm{~h}$ and was then cooled to $58^{\circ}$. At this stage the second portion of $5 \mathrm{~g}$ malted sorghum was added, and after a further $2 \mathrm{~h}$ at $58^{\circ}$ it was cooled to $30^{\circ}$, the brewer's yeast was added and fermentation was allowed to continue for a further $24 \mathrm{~h}$. Throughout the fermentation process the volume was kept constant by replacing water lost by evaporation.

\section{Measurement of radio-Fe absorption}

On successive mornings the two products which were to be compared were administered after an overnight fast. Only water was allowed during administration of the test material and for $4 \mathrm{~h}$ afterwards. Blood samples were obtained $\mathrm{I} 4 \mathrm{~d}$ later for determination of the ${ }^{\mathrm{B}} \mathrm{Fe}$ and ${ }^{50} \mathrm{Fe}$ contents, the haemoglobin concentration, the plasma $\mathrm{Fe}$ concentration, the unsaturated-Fe-binding capacity and in some instances the plasma ferritin concentration. Unless otherwise stated absorptions were expressed as a proportion of the total iron given.

\section{Isotopic and chemical methods}

Duplicate blood samples $(10 \mathrm{ml})$ and duplicate portions of the appropriate standards were prepared for differential radioactivity determination by the method of Katz et al. (1964). The activities of ${ }^{\mathrm{B5}} \mathrm{Fe}$ and ${ }^{59} \mathrm{Fe}$ in the processed samples were determined in Instagel scintillant (Packard Instrument Co., Downers Grove, Illinois, USA) using a liquid-scintillation spectrometer (Packard Tri-Carb AAA Spectrometer Model no. 3375) which automatically corrected for quenching. The counting efficiency was $24 \%$ for ${ }^{55} \mathrm{Fe}$ and $42 \%$ for ${ }^{58} \mathrm{Fe}$ at optimal gain and window settings. All absorption values were calculated on the basis that $100 \%$ of the absorbed radioactivity was present in the haemoglobin of circulating erythrocytes, and that the blood volume for each subject was $65 \mathrm{ml} / \mathrm{kg}$ body-weight.

Plasma Fe concentrations were measured by the International Committee for Standardization in Hematology (1971) method and unsaturated-Fe binding capacities by the method of Herbert et al. (1967). The Fe content of digested food samples was estimated by a modification (Bothwell \& Finch, 1962) of the method of Lorber (1927). The plasma ferritin concentrations were measured by the immunoradiometric method of Miles et al. (1974).

\section{Subjects}

Absorption of radio-Fe from maize and sorghum gruels and their fermentation products was measured in volunteer normal subjects and hospital patients, including male medical staff members, female nurses, Fe-deficient females, males convalescing from traumatic disorders and females recovering from various acute medical diseases. Because of the variety of subjects studied, results obtained in different experiments could not be compared with each other. In each experiment, however, the use of the double-isotope technique permitted the effect of the variable under examination to be tested with each subject acting as his or her own control. 


\section{Ethical considerations}

Written consent was obtained from all subjects after the nature of the investigation had been explained to them. Before the study was started, approval was obtained from the Committee for Research on Human Subjects of the Faculty of Medicine, University of the Witwatersrand, Johannesburg. It was calculated that if the administered doses of radioisotopes were completely retained, the total radiation averaged over 13 weeks would be approximately $20 \%$ and $0.2 \%$ of the permissible whole-body burden for continuous exposure to ${ }^{59} \mathrm{Fe}$ and ${ }^{55} \mathrm{Fe}$ respectively (International Commission for Radiation Protection, I960).

\section{RESULTS}

Measures of Fe status, namely the concentrations of haemoglobin, serum $\mathrm{Fe}$ and serum ferritin, and percentage saturation of transferrin (Table I) were found to differ somewhat between the groups studied and it is therefore impossible to compare results from separate experiments.

\section{Fe absorption from beer as compared with gruel}

In an initial experiment in thirteen subjects the absorption of Fe from commercial beer was compared with that from the constituents used in its preparation. In this and subsequent experiments there was a considerable variation in individual values. All values were therefore logarithmically transformed in order to correct for positive skew. The geometric mean (士SD) absorption from the beer of $7 \cdot 7 \%(4 \cdot 2-14 \cdot 1)$ was significantly greater $(t=7 \cdot 57$, $P<0.0005)$ than the geometric mean $( \pm \mathrm{SD})$ of $0.6 \%(0.2-\mathrm{I} \cdot 8)$ from the gruel (Table $\mathrm{I})$.

This difference could have been the result of one or more changes that occur during the fermentation process. First, there is a fall in the solid content from 162.5 to $50 \mathrm{~g} / \mathrm{l}$. This reduction results from the conversion of starch to sugar and finally to ethanol and from the removal of some of the remaining material by filtration at the end of fermentation. Secondly, $5 \mathrm{ml} \mathrm{lactic} \mathrm{acid/l}$ is produced during the first fermentation process and remains in the final product, since it is not sufficiently volatile to be distilled off during the boiling that occurs between the two fermentations. Its presence not only reduces the $\mathrm{pH}$ of the beer to 3.5 but also provides a potential ligand for Fe. Finally, ethanol $30 \mathrm{ml} / \mathrm{l}$ is formed during the second fermentation. A series of experiments was therefore carried out to find out the relative importance of these different factors in potentiating Fe absorption from sorghum beer.

\section{The effects of suspended solid material}

The results of several studies indicated that if solids were present in sufficient amounts, Fe absorption was depressed even when ethanol or lactic acid was present (Table I).

In the first study, which was carried out in seven patients, the geometric mean ( $\pm S D$ ) absorption of Fe from a thick gruel ( $162.5 \mathrm{~g}$ solids/1) was $\mathrm{I} \cdot 2 \%(0.4-3.9)$. When $30 \mathrm{ml}$ ethanol/1 was added to it the mean $( \pm S D)$ absorption of $2 \cdot 3 \%(1 \cdot 1-4 \cdot 9)$ was moderately greater, but the increase was not statistically significant $(t=2.35, P>0.05)$. In contrast, when a similar gruel containing $162.5 \mathrm{~g}$ solids/ 1 and $30 \mathrm{ml}$ alcohol $/ 1$ was compared in six subjects with commercially prepared beer ( $50 \mathrm{~g}$ solids/1), there was a marked difference in absorption, with geometric mean $( \pm S D)$ values $2.0 \%(1 \cdot 0-3.9)$ and $8.9 \%(3.9-20.4)$ respectively $(t=4.39, P<0.01)$.

When the solid content of the gruel was reduced to $100 \mathrm{~g} / \mathrm{l}$, a similar pattern was noted. In one experiment a comparison was made in fifteen subjects between the absorption of $\mathrm{Fe}$ from this gruel and from the same gruel after the Lactobacillus fermentation. The geometric mean $( \pm \mathrm{SD})$ absorption from the gruel was $0.2 \%(0.1-7 \cdot 7)$ as compared with 


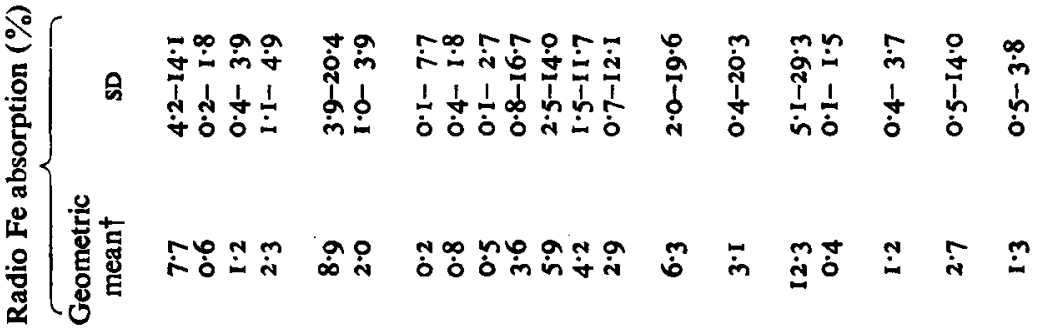

$\frac{\text { ก }}{8}$

竞

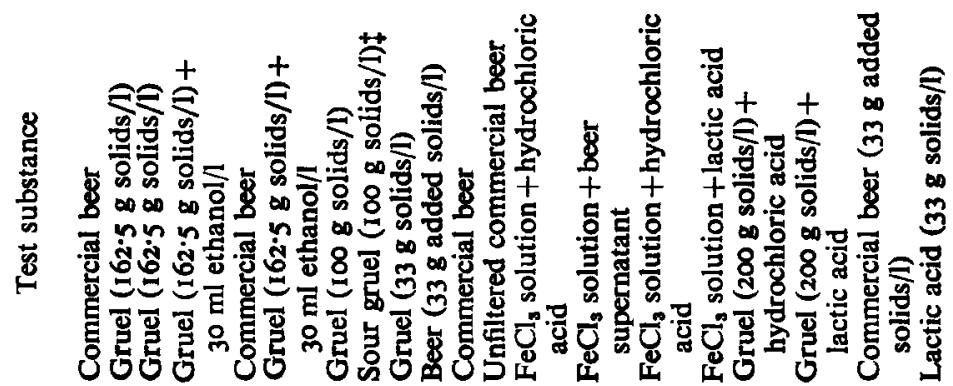

悬

$+$

ì $\underset{1}{+}$

$\stackrel{\sim}{\dot{Z}}$



官

क

\$

5

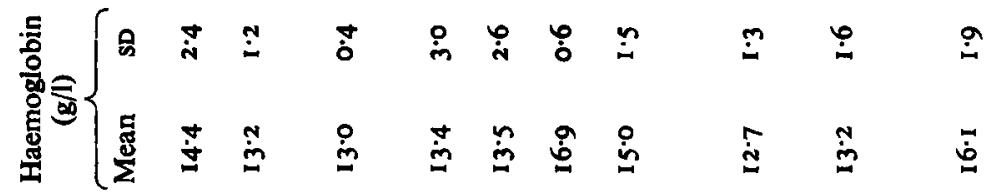

$\dot{-i}$

苛

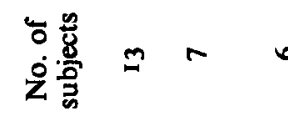

:

\%ั

$\stackrel{9}{\stackrel{5}{*}}$

จ

5

ริ



过 
$0.8 \%(0.4-1 \cdot 8)$ from the fermented gruel. The difference, though very small, was significant $(t=5.57, P<0.0005)$.

In a final series of studies, the solid content was reduced even further to see whether there were any factors in beer that could counteract its inhibitory action. Thirteen subjects were given $3 \mathrm{mg}$ labelled $\mathrm{FeCl}_{3}$ on two separate mornings. On the one occasion it was given in $400 \mathrm{ml}$ commercial beer to which cereal had been added, so that the final solid content was raised by $33 \mathrm{~g} / \mathrm{l}$. On the second morning water was substituted for the beer. The geometric mean $( \pm \mathrm{SD})$ absorption from the thickened commercial beer was $3.6 \%(0.8-16 \cdot 7)$ which was significantly greater $(t=4 \cdot 16, P<0.005)$ than the absorption of $0.5 \%(0 \cdot 1-2 \cdot 7)$, which was obtained when water was present instead of beer. In the last experiment the grits that represent the residual solids left in beer at the end of the fermentation process were not removed by filtration in the usual way, in order to find out whether they exerted an inhibitory effect on Fe absorption. The absorption of $\mathrm{Fe}$ from this unfiltered beer was compared with the absorption from filtered commercial beer in nine subjects. The geometric mean ( \pm SD) absorptions were $4.2 \%(\mathrm{I} \cdot 5-\mathrm{II} \cdot 7)$ and $5.9 \%(2 \cdot 5-14 \cdot 0)$ respectively, values which were not significantly different $(t=2.01, P>0.05)$. These results suggest that the coarse material removed in the final centrifugal filtration is not an inhibitor of $\mathrm{Fe}$ absorption.

\section{Possible promoters of Fe absorption in sorghum beer}

In the experiments described previously, some evidence was obtained which suggested that the inhibitory effects of the cereals present in gruel on Fe absorption were reduced by both the Lactobacillus and the ethanol fermentations. Furthermore, ethanol in the same concentration as that present in beer seemed to have a modest enhancing effect on the absorption of $\mathrm{Fe}$ in a gruel. In a final group of studies, attempts were made to discover the nature of the other possible promoting factors in beer.

The first experiment was carried out to find out whether it was the low $\mathrm{pH}$ of beer that was responsible for enhancing $\mathrm{Fe}$ absorption. Commercial beer was centrified at $300 \mathrm{~g}$ for $\mathrm{I} h$ to remove all suspended solid. The absorption of $3 \mathrm{mg}$ radio $\mathrm{Fe}$ from $300 \mathrm{ml}$ of this clarified beer was compared with that from $300 \mathrm{ml}$ of aqueous radio- $\mathrm{Fe}$ adjusted to the same $\mathrm{pH}$ with hydrochloric acid. The geometric mean ( \pm SD) absorption from beer of $6.3 \%(2 \cdot 0-19 \cdot 6)$ in thirteen subjects was greater than the $2.9 \%(0.7-12 \cdot 1)$ absorbed from the acidified aqueous solution, a difference which was statistically significant $(t=2 \cdot 27$, $P<0.05$ ).

In a second group of experiments the possible role of lactic acid was examined. The absorption of $\mathrm{Fe}$ from a solution of $\mathrm{FeCl}_{3}\left(3 \mathrm{mg} \mathrm{Fe}, 2.5 \mu \mathrm{Ci}{ }^{59} \mathrm{Fe}\right.$ ) containing $2 \mathrm{ml}$ lactic acid/l was compared in thirteen subjects with that from a $\mathrm{FeCl}_{3}$ solution adjusted to the same $\mathrm{pH}(2 \cdot 5)$ with $\mathrm{HCl}$ and labelled with ${ }^{55} \mathrm{Fe}$. The geometric mean $( \pm \mathrm{SD})$ absorption from the solution containing lactic acid was $12 \cdot 3 \%(5 \cdot 1-29 \cdot 3)$ which was significantly higher $(t=$ $2.4 \mathrm{I}, P<0.05)$ than the mean of $3.1 \%(0.4-20.3)$ from the solution containing $\mathrm{HCl}$. The ability of lactic acid to counteract the inhibitory effects of suspended cereal solids was tested in a further twenty-one subjects. Solutions were administered as in the previous experiment, except for the addition of maize meal to provide a final concentration of solids of $200 \mathrm{~g} / \mathrm{l}$. The resultant gruels were boiled with stirring for $10 \mathrm{~min}$ before administration. While $\mathrm{Fe}$ absorption was significantly reduced under such circumstances, that from the gruel containing lactic acid was significantly better $(t=4.62, P<0.0005)$ than that from the $\mathrm{HCl}$ solution, with geometric mean $( \pm \mathrm{SD})$ values of $\mathrm{I} \cdot 2 \%(0 \cdot 4-3 \cdot 7)$ and $0.4 \%(0 \cdot \mathrm{I}-\mathrm{I} \cdot 5)$ respectively.

Since the solid content of the gruels administered in the previous experiment was large, a final experiment was carried out in which a direct comparison was made between the absorption of $\mathrm{Fe}$ from commercial beer as compared with a lactic acid solution adjusted to 
the same $\mathrm{pH}$ in the presence of only $33 \mathrm{~g}$ added solids/1 (equal quantities of maize meal and sorghum). In each instance the final volume was $600 \mathrm{ml}$, which was made up of $400 \mathrm{ml}$ of the solution being tested and $200 \mathrm{ml}$ of a boiled gruel containing the added solids. The $\mathrm{Fe}$ content of the final mixture was made up to $3 \mathrm{mg}$ with either ${ }^{65} \mathrm{FeCl}_{3}$ or ${ }^{69} \mathrm{FeCl}_{3}$. The experiment was carried out in six subjects. While the geometric mean ( $\pm \mathrm{SD})$ absorption of $2.7 \%$ $(0.5-1.4)$ from the beer was somewhat greater than that from the lactic acid solution $1.3 \%(0.5-3.8)$, the difference was not statistically significant $(t=1.67, P>0.05)$. It was, however, noteworthy that absorption from the beer was greater in all four subjects with absorption rates over $1.0 \%$; respective values were $1.4 \%$ v. $1.0 \%, 3.5 \%$ v. $0.8 \%$, $7.6 \%$ v. $1.3 \%$ and $36 \%$ v. $10.3 \%$.

\section{Nature of Fe solubilized during fermentation}

The leaching of solid Fe during the fermentation process was studied by brewing beer in the presence of analytical grade Fe wire and isotopic tracer. In Fig. I the fall in the pH during the Ist fermentation and the accompanying slow increase in the soluble Fe content of the beer up to $6.5 \mathrm{mg} / \mathrm{l}$ are shown. The soluble fraction contained $53 \%$ of the isotope, but when the brew was boiled it decreased to $15 \%$. During the subsequent ethanolic fermentation at $18^{\circ}$ the Fe content of the supernatant solution increased rapidly to $89 \mathrm{mg} / \mathrm{l}$ and the percentage of isotope in the soluble fraction increased to 42 .

Several techniques were used to examine the nature of the radio-Fe in the clear supernatant solution obtained by centrifugation of the final product. Addition of 9 vol. absolute ethanol or acetone precipitated $80 \%$ and $87 \%$ of the radioactivity respectively. These precipitates were sparingly soluble in water. Of the total radioactivity $91 \%$ was ultrafiltrable using an Amicon PM 30 membrane. During the dialysis of $4 \mathrm{ml}$ supernatant fraction with $75 \mathrm{ml}$ of water, $61 \%$ of radio-Fe crossed the membrane, compared to only $16 \%$ if it was neutralized with sodium bicarbonate before dialysis. During neutralization the solution took on a blackish tinge, and shortly after dialysis commenced, a precipitate formed.

An attempt was made to isolate the radio-Fe compound using $16 \times 230 \mathrm{~mm}$ Sephadex Gro columns equilibrated and eluted with either water or a solution of $\mathrm{HCl}$ having the same pH as the supernatant solution. With water as eluant two distinct peaks were obtained, the smaller after $15 \mathrm{ml}$ and the larger between 20 and $33 \mathrm{ml}$. With $\mathrm{HCl}$ a single peak was eluted between 14 and $24 \mathrm{ml}$. However, only $50 \%$ of the radioactivity was recovered from either column and the remaining radio-Fe was distributed through the entire length of the column.

The possibility that the Fe was present as ferrous lactate was considered. Its chromatographic behaviour was compared with a salt prepared from Fe wire and lactic acid. Neither compound seemed to be stable in ascending chromatography on Whatman No. 4 paper using butanol-acetic acid-water (120:30:50, by vol.). Nevertheless, it appeared that the two substances were not identical.

\section{DISCUSSION}

In the initial experiment carried out in this study it was found that ten times as much Fe was absorbed from the traditional maize and sorghum beer consumed by the Southern African black population as from a gruel made from the same ingredients. There are several changes that occur during the brewing process that might account for such a difference. First, there is a marked decrease in the solid content, due both to the conversion of starch to sugar and ethanol and to the removal of coarse material by filtration. Secondly, ethanol is formed, to give a final concentration of $30 \mathrm{ml} / 1$. Thirdly, lactic acid $(5 \mathrm{ml} / \mathrm{l})$ is formed, which results in the beer having a $\mathbf{p H}$ of $3.5-4^{\circ}$. Finally, in addition to these three changes which are known to occur during brewing, it is possible that one or more Fe chelators may be produced by micro-organisms. 


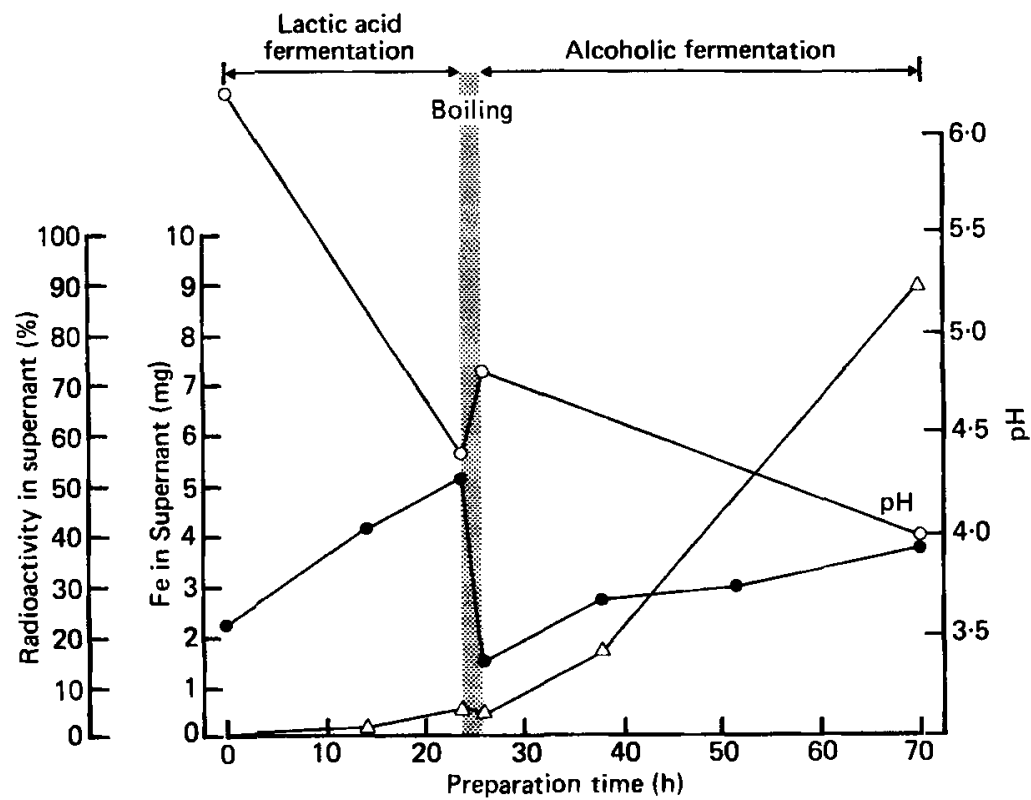

Fig. I. Release of $(-\ldots)$ radio-iron and of $(\Delta-\Delta)$ inorganic $\mathrm{Fe}$ into the supernatant fraction during the preparation of maize (Zea mays) and sorghum (Sorghum vulgare) beer. $(\mathrm{O}-\mathrm{O}), \mathrm{pH}$. (Radio-Fe and analytical grade Fe wire were added before brewing.) For details of preparation of beer, see page 272 .

The marked inhibitory effect of solid material on Fe absorption (maize meal with or without sorghum) was evident in a number of studies, especially in those in which the solid content of the administered material was $100 \mathrm{~g} / \mathrm{l}$ or more. Nevertheless, it seemed that absorption of $\mathrm{Fe}$ from beer was decreased less by the addition of solids than was the absorption of Fe from gruel. This effect was particularly evident in the study in which the solid content of the gruel was reduced to $33 \mathrm{~g} / \mathrm{l}$. It was of some interest to note that the coarse material which is removed at the end of the fermentation process did not inhibit the absorption of the $\mathrm{Fe}$ in beer. This suggests that starch may be the solid that inhibits $\mathrm{Fe}$ absorption, since it diminishes in quantity by conversion to ethanol during fermentation.

Attempts to identify possible factors in sorghum and maize beer that promote $\mathrm{Fe}$ absorption did not give clear-cut results. In a previous study it was shown that ethanol enhances $\mathrm{Fe}$ absorption, probably by stimulating the output of $\mathrm{HCl}$ by the stomach (Charlton et al. 1964). In the present investigation it was possible to show that the addition of $30 \mathrm{ml}$ ethanol/l to thick gruel (162.5 g solids/l) did increase Fe absorption, but only modestly. The relatively small effect may, however, have been due to the high solid content of the gruel, since absorption of $\mathrm{Fe}$ from beer $(30 \mathrm{ml}$ ethanol/1) to which $33 \mathrm{~g}$ solids/l were added was greater than from a lactic acid solution similarly treated. At the same time, evidence was obtained that lactic acid was probably also a factor promoting $\mathrm{Fe}$ absorption in maize and sorghum beer. This was not only the result of its low $\mathrm{pH}$, since four times as much $\mathrm{Fe}$ was absorbed from a $\mathrm{FeCl}_{3}$ solution containing lactic acid than from a similar solution adjusted to the same $\mathrm{pH}$ with $\mathrm{HCl}$. It is possible, therefore, that lactic acid acts as a chelator which enhances $\mathrm{Fe}$ absorption from beer.

Whether other factors promoting Fe absorption are elaborated during fermentation is not clear. Such factors could be intermediates or products of the two fermentation processes other than lactic acid. Possible complexers of Fe are ATP (Bartlett, 1976) and enterochelins, 
which are secreted by certain micro-organisms to obtain Fe for themselves from the environment (Rosenberg \& Young, 1974). C. M. Peterson and A. Cerami (personal communication) found evidence of such a compound in a culture prepared from commercial sorghum beer, but its quantitative significance has not been established. Substances of this type are currently exciting some interest because they may prove useful as additives for food Fe fortification or as chelators suitable for mobilizing $\mathrm{Fe}$ in states of overload.

Preliminary information on the chemical nature of the Fe present in beer was obtained. The results of dialysis and ultrafiltration studies indicated that a large proportion of the soluble Fe was present in an ionic form or as a low-molecular-weight compound. Very little was dialysable after raising the $\mathrm{pH}$ to $7 \cdot 0$, which suggests that little or no chelator was present that was able to stabilize $\mathrm{Fe}$ in a soluble form at neutral $\mathrm{pH}$. Attempts at further identification were not successful, and no positive evidence to suggest that the major complex was Fe lactate was obtained.

This work was supported by a grant from the South African Atomic Energy Board. The authors wish to thank the officials of the West Rand Administration Board who not only supplied both beer and the ingredients for its preparation, but also gave invaluable advice throughout this study.

\section{REFERENCES}

Bartlett, G. R. (1976). Biochem. Biophys. Res. Comm. 70, 1063.

Bothwell, T. H. \& Finch, C. A. (1962). In Iron Metabolism, Ist ed., p. I8. London: J. \& A. Churchill.

Bothwell, T. H. \& Isaacson, C. (1962). Br. med. J. i, 522.

Bothwell, T. H., Seftel, H. C., Jacobs, P., Torrance, J. D. \& Baumslag, N. (1964). Am. J. clin. Nutr. I4, 47. Buchanan, W. M. (I969). Central Afr. J. Med. 15, I05.

Charlton, R. W., Jacobs, P., Seftel, H. C. \& Bothwell, T. H. (1964). Br. med. J. ii, I427.

Herbert, V., Gottlieb, C. W., Lau, K. S., Gervirtz, N. R., Sharney, L. \& Wasserman, L. R. (1967). J. Nuc. Med. 8, 529.

International Commission for Radiation Protection (1960). Report of Committee II on Permissible Dose of Internal Radiation (1959). I.C.R.P. Publ. no. 2. Oxford: Pergamon Press.

International Committee for Standardization in Hematology (1971). Br. J. Haemat. 20, 451.

Katz, J. H., Zoukis, M., Hart, W. L. \& Dern, R. J. (1964). J. Lab. clin. Med. 63, 885.

Layrisse, M., Cook, J. D., Martinez, C., Roche, M., Kuhn, I. N., Walker, R. B. \& Finch, C. A. (1969). Blood 33, 430.

Layrisse, M., Martinez-Torres, C., Cook, J. D., Walker, R. \& Finch, C. A. (1973). Blood 4I, 333.

Lorber, L. (1927). Biochem. Z. 181, 391.

MacPhail, A. P., Simon, M. O., Torrance, J. D., Charlton, R. W., Bothwell, T. H. \& Isaacson, C. (I979). Am. J. clin. Nutr. 32, 127.

Miles, L. E. M., Lipschitz, D. A., Bieber, C. P. \& Cook, J. D. (1974). Analyt. Biochem. 6r, 209.

Rosenberg, H. \& Young, I. G. (1974). In Microbial Iron Metabolism, pp. 67-82 [J. B. Neilands, editor]. New York: Academic Press.

Sayers, M. H., Lynch, S. R., Jacobs, P., Charlton, R. W., Bothwell, T. H., Walker, R. B. \& Mayet, F. (1973). Br. J. Haemat. 24, 209.

Walker, A. R. P. \& Arvidsson, U. B. (1953). Trans. R. Soc. trop. Med. Hyg. 47, 536. 